\title{
The potential of economic ore deposits related to meteorite impact structures
}

\author{
Rui Zhu \\ Department of Applied Geology,WA School of Mines,Curtin Univerisity, Perth, Australia \\ zrzrnn@163.com
}

Keywords: Impact structure; impact metamorphism; impact signature; economic and geological significance

Abstract: At present, research on impact tectonics mainly covers the following aspects: 1 . The structure and formation mechanism of the impact crater; 2. The ore-forming mineralization in impact structures; and 3. The economic and geological significance of impact structures. The study of impact structure not only has academic significance but also practical economic and geological significance. Economic deposits associated with impact structures range from world-class to relatively local deposits. There are three types of deposits: progenetic, syngenetic and epigenetic. There is increasing evidence that large-scale impact structures are often associated with economic deposits. Many impact structures can be targets for resource exploration but still need to be discovered. The exploration of impact structures is hindered by technology and sea-land erosion, and a considerable number of craters have been likely buried. Based on the economic deposits associated with these structures, further resource discovery and extraction has great potential.

Original article, Published date: 2018-05-22

DOI: $10.23977 /$ geors.2018.11011

ISSN 2523-2592

https://www.clausiuspress.com/journal/GEORS.html

\section{Introduction}

In recent years, the influence of extra-terrestrial objects on Earth geology has been considered as an interesting influence. With the development of planetary exploration, our understanding of the importance of impact cratering has undergone fundamental changes. This shows that the impact 
cratering affects almost all planetary surfaces. As part of the solar system, the Earth experienced a similar impact history as other planetary bodies. As far as the current discovery is concerned, about 190 impact structures have been found on Earth (Earth impact database, 2018). However, these apparently represent a small part of the Earth impact history. Solid surfaces of other celestial bodies in the solar system contain a larger number of impact structures, but due to the current technical reasons, it is almost impossible to carry out detailed geological research. Only the surface of Moon, Mars, Mercury and some moons around other planets have been studied. In the future exploration of the universe, humanity will have to rely on all kinds of resources derived from space mining. In recent years, the Moon, Mars surface, and asteroid mining have been hot topics for research (You and Liu, 2008). Because it is hard and expensive to collect samples and data from the other planets, the research of Earth's impact structure becomes more important now. Therefore, studying the economic potential of impact structures on Earth is the focus of the current research. This review will summarise previous research about terrestrial impact structures and make a general discussion about the impact structures of Australia, and then it will focus on the impact records of Western Australia.

\section{Background information of impact structures}

An impact structure is a structural feature formed by the rapid impact of a substance such as an asteroid or comet nucleus on the surface of a planet. At present, research on impact structures includes the following four aspects: 1) the morphology and formation mechanisms of meteorite impact craters; 2) impact metamorphism and deformation; 3) numerical simulation and experimental study of impact; 4) impact effect on economic geological significance (You and Liu, 2008). Meteorite impact metamorphism is a kind of metamorphism under extreme conditions. Unlike general metamorphism, its heat source is not from the interior of the earth and has nothing to do with movement of plates. It is a non-internal geological force. Impact metamorphism and its products, impacted metamorphic rocks, are important indicators for the identification of meteorite impact process. Meteorite impact metamorphism is undoubtedly a catastrophe to the earth, but many meteorite craters have economic value.

\subsection{Formation Mechanisms of Impact Craters}

If a meteorite with a diameter of $1 \mathrm{~km}$ (with density at $8.0 \mathrm{~g} \mathrm{~cm}^{3}$ ) hits the surface at a speed of 25 $\mathrm{km} / \mathrm{s}$, its kinetic energy is $\mathrm{E}=1 / 2 \mathrm{mv}^{2}=1.31 \times 10^{21} \mathrm{~J}$. This kinetic energy is equivalent to an explosive energy of $3.12 \times 10^{11}$ t of TNT explosive. The Indonesian earthquake only had an energy of $184 \times 10^{16} \mathrm{~J}$ (Zhai, Ou and Chang, 2001). Therefore, the impact of meteorite on the Earth is a major catastrophe (French and Koeberl, 2010). The process of impact cratering can be broadly divided into three stages: compression, excavation, and adjustment after formation. The highpressure transient compression wave formed in the compression stage is called a shock wave. With a speed of $10 \mathrm{~km}$ per second, the shock wave pressure can reach several hundred GPa. When the shock wave pressure reaches 1 to $30 \mathrm{GPa}$, the target rocks break, more than $30 \mathrm{GPa}$ of granite rock selectively melts partially, $>60 \mathrm{GPa}$ granitic rocks is evaporated into a gas (Zhai, Ou and Chang, 2001). Behind the shock wave is the release wave, which acts as a decompression wave. All meteorite fragments, melts, and evaporates are ejected at high speed along the interface between the shock wave and the sparse wave and dug into pits. At the same time, the splattered rock material piles up on the pit to form a sediment layer. The sequence of the sedimentary layer is opposite to the stratum where the meteorite impacted, the upper throw is under, and the lower one is upper. After the meteorite impact crater forms, it will be affected by gravity and rock mechanics, and various adjustments and deformation will occur. First, bulges often appear in the middle of a crater due to 
the rebound of impact, and then the crater wall is collapsed by gravity and debris is projected inward to form crater-filled breccia, at last, there are radial and concentric fractures due to bulging (Fang et.al, 2008).

\subsection{The morphology and structure of meteorite impact craters}

On planets or satellites that are not shielded by an atmosphere, tiny cosmic dust can hit microscopic pits on their surface. The Earth's atmosphere is as thick as 1000 kilometres. Some smaller diameter meteorites disappear in less than one second when they entered the atmosphere because of the high temperatures and instantaneous high-pressure bursts and gasification of the combustion, so most of the craters on Earth's surface can be found in larger diameters. (Fang et.al, 2008). According to the shape and structure of the meteorite crater, it can be roughly divided into two categories: simple and complex (Figure 1).

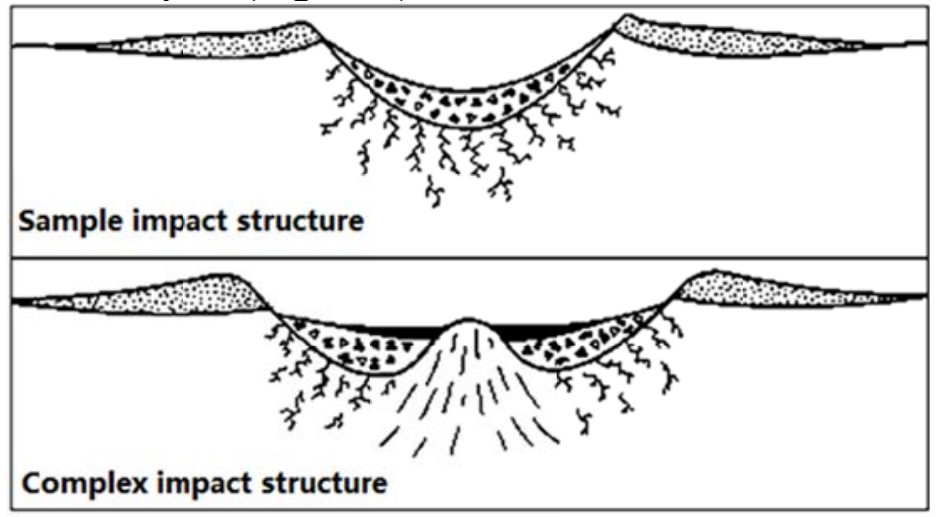

Fig.1 Simple impact crater (upper)and complex impact crater (lower). (You and Liu, 2008)

The shape of a simple meteorite crater, depth/diameter $=1 / 5$ to $1 / 7$, is like a shallow bowl. There is a crater edge which formed by the ejected materials. The ejected material has a deposition range of 2 times the crater diameter (Fang et. al, 2008). The particle size of the ejected material decreases with distance from the crater edge. There is a typical example in Arizona, USA, the Barringer Crater, impact age: 4.9 million years, $1.2 \mathrm{~km}$ in diameter and 100 meters deep (Kring, 2007).

Complex impact structures: The bottom of the crater often has a centre uplift, and the crater has collapsed and is fractured. There are two causes of uplift in the centre: (1) Rocks in the bottom target area rebound due to decompression; (2) Material collapse after crater excavation. Complex meteorite craters often induce magmatic activity, which hit falling breccias and often covered under lava (Zhai, Ou and Chang, 2001). There is a typical example in Sudbury, Canada, it is around $15000 \mathrm{~km}^{2}$. Including the entire Sudbury Igneous Complex (SIC) and floor breccia. The Sudbury structure is located at the interface between the Proterozoic Huron Supergroup and the Archean basement. Within $17 \mathrm{~km}$ of the SIC, can find the structural mark of impact of the meteorite - shatter cone; There are distributions of impacted metamorphic rocks such as suevite and pseudotachylite around the SIC. In many places, impact breccia forms Cu-Ni-PGE (PGM) deposits which are still being mined now (Lazorek et.al 2006).

Except for some young impact structures, most of them are destroyed by later geological actions. Taking the Popigai impact structure of the Anabar shield in Siberia as an example, damage related to the structure is apparent. It appears as a series of fault blocks of different widths and different vertical displacements. The boundaries between fault blocks can be identified from the development of linear water systems and linear cliffs in crater rocks. Sometimes it can be seen the linear deposition zone where the later impact sediment is thicker (Mashchak and Naumov, 2005). 


\subsection{Late modification meteorite impact crater}

The formation of meteorite impact craters, which are eroded and destroyed by later epigenetic effects, then it is affected by the superposition and reconstruction of late tectonic function. The later transformation of the meteorite crater includes landslides, erosion, filling, and volcanism. Therefore, older and smaller meteorite impact craters are often difficult to preserve on Earth. The $1 \mathrm{~km}$ impact crater is beyond recognition for millions of years (You and Liu, 2008). Therefore, it is difficult to find meteorite impact craters that are heavily eroded and buried beneath thick sedimentary layers. The northern part of the Baltic Sea in Sweden and Finland (the Svecofennian), the basal age is $1.9 \mathrm{Ga}$, and the adjacent young orogenic belt is $1.5 \sim 1.8 \mathrm{Ga}$, the total area of 1.56 million square kilometres, 22 meteorite craters have been discovered and confirmed in the area (Earth impact database, 2018).

There are seven possible meteorite impact craters. There are also a dozen speculations of the impact structures that survived after long geological periods. The middle-small scale meteor impact craters have been found in sedimentary layers on the crystaline rock of Svecofennian shield and on the Russian platform, and even in sedimentary rocks below the surface of the epeiric sea (Fig 2). They are completely or partially eroded and destroyed. The period of the cratering, the Early Palaeozoic, was a period of multiple impact events and there are many remaining meteorite impact craters. This shows that there is a history of uneven erosion in this area, and there are many hidden (buried) impact structures.

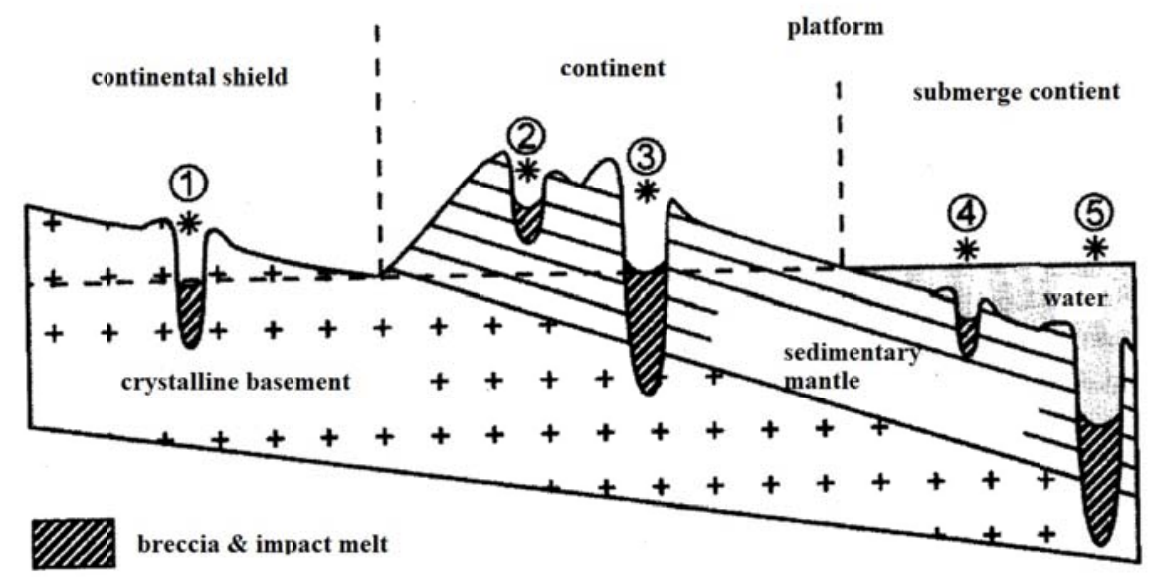

Fig.2 Typical impact geological settings in the Svecofennian domain (You and Liu, 2008)

\subsection{Identification of impact structures}

As already mentioned, crater is subject to erosion and structural damage after their formation. Especially for craters with a long geological history, it is difficult to fully restore its morphology. Many old impact structures are hidden under the sedimentary layers, and some are even hidden under the seabed. The combination of petrology, remote sensing of geology and geophysical methods can effectively find them. In terms of geology, it mainly depends on the following identification marks:

1) The debris of meteorites. For younger crater pits, there is often the debris of meteorite. Collecting the samples from the crater and the edge of crater sedimentary, and panning carefully, and then analyse the heavy suite in the samples, to find the iron nickel chondrite and other more precise criteria (Grieve and Pilkington, 2002). 
2) Surface morphology. The appearance of the young impact crater can be found in aerial photographs. Its main feature is that it has a ring-like raised crater edge. The sequence of the projectile around the crater is the opposite of the ground sequence of the meteorite crater. In addition, there are secondary pits due to massive debris bombardment (Grieve and Pilkington, 2002).

3) Impact metamorphic products. The most common are pseudotachylite from suevite and fused mass, some large complex impact structures have multiple pseudotachylite zones. Some minerals are unique to meteorites, such as chreibersite, daubréelite and heideite, these minerals are rarely or never find on Earth. Geochemical characteristics mainly refer to the occurrence of strong material differentiation in the impact process and its follow-up effects. Some volatile components lose more, resulting in an abnormal enrichment of the iron-producing elements, especially the platinum group elements. For example, there are some magnitude differences between the content of antimony in some impact structures or in the stratigraphic profile and the average content of antimony in the crust. (Fang et. al, 2008).

4) Shatter cone. There is a pronounced stripe-like conical structure on the fracture surface of the rock which on the surface of impact target. Strip lengths from less than $1 \mathrm{~cm}$ to several meters, the stripes disperse from the top of the cone to the side, showing a horsetail shape. The appearance of a shatter cone indicates that the pressure of the shock wave can reach 2 to $25 \mathrm{GPa}$ (Fang et. al, 2008). Measure the direction of the cone top can determine the centre of the shock wave (French, 2003).

\section{Economic Geology Significance}

\subsection{Impact record of the world}

The relationship between impact structure and mineralization has always been very sensitive and meaningful. In some cases, these deposits have a very high economic value (such as $\mathrm{Cu}-\mathrm{Ni}$ deposit in Sudbury, Canada and Au deposit in Vredefort Dome, South Africa) (Reimold et.al. 2005). Of the 190 known impact craters, about $25 \%$ are known to be associated with economic deposits, about half of which are being mined. Currently, it is conservatively estimated that the annual income of these mines exceeds US\$12 billion. This estimate is mainly based on gold and uranium deposits with an annual income of more than US\$7 billion in the Vredefort structure of South Africa and North American deposits with a revenue of more than US\$5 billion. It excludes the extraction of construction materials, tourism or income from hydroelectric power generation, such as the tourism industry in Chesapeake Bay, USA and the 200 million dollars per year of hydroelectric power in the Manicouagan crater in Canada (Grieve, 2013).

The origin and position of economic deposits in impact structures are controlled by factors related to the impact process and the specific properties of the target sites. The types of deposits which formed in or nearby craters are classified into three categories based on their formation time relative to impact events:1) progenetic; 2) syngenetic; and 3) epigenetic (Grieve, 2005). 
Table 1 Some economy deposits in impact structure. (Reimold et.al, 2005)

\begin{tabular}{|c|c|c|c|c|}
\hline Crater Name & Location & Diameter $(\mathrm{km})$ & Age (Ma)* & Economic Interest \\
\hline Chicxulub & Yucatan, Mexico & 150 & 64.98 & Hydrocarbons; impact diamonds \\
\hline Sudbury & Ontario, Canada & 130 & 1850 & $\mathrm{Ni}, \mathrm{Cu}, \mathrm{PGE}$; impact diamonds \\
\hline Popigai & Russia & 90 & 35.7 & Impact diamonds \\
\hline Kara & Russia & 65 & 70.3 & Impact diamonds, Pyrite \\
\hline Siljan & Sweden & 52 & 376.8 & $\mathrm{~Pb}-\mathrm{Zn}$; winter sport \\
\hline Puchezh-Katunki & Russia & 40 & 167 & Impact diamonds, mercury; zeolite \\
\hline Usi-Kara & Russia & 25 & 70.3 & Pyrite \\
\hline Steen River & Alberta, Canada & 25 & 91 & Hydrocarbons \\
\hline Ries & Germany & 24 & 15.1 & Impact diamonds \\
\hline Obolon' & Ukraine & 20 & 169 & Hydrocarbons \\
\hline Kentland & Indiana, U.S.A. & 13 & 97 & $\mathrm{~Pb}-\mathrm{Zn}$ \\
\hline Ternovka & Ukraine & 11 & 280 & Iron ore; impact diamonds; uranium \\
\hline
\end{tabular}

Progenetic economic deposits are those deposits which formed by the geology concentration activity before the impact event. Impact events have led to a redistribution in those deposits and sometimes the impact event brought them to the near surface where they can be mined. A syngenetic deposit is a direct result of the impact process that occurs during or after the impact event. The deposit formed by phase transitions and melting because the impact event. Hydrothermal deposits are also considered to be syngenetic because heat sources are the direct result of shock events. Epigenetic deposits formed in closed basin topography which formed by the impact event. In this table, it only focus on the deposits which are larger and world-class. (Table 1) It can be seen that various minerals form by impact including diamonds; Ni-Cu PGE deposits; Uranium and rare earth elements; oil, natural gas, coal and many non-metallic deposits.

\subsection{The impact record from Australia}

Compared to other continents, the Australian mainland has the best-preserved meteorite impact record on Earth and it continues to discover new craters.

There are 27 recorded impact structures in Australia. The earliest recorded example of impact craters in Australia is Henbury crater in central Northern Territory, Australia. The Henbury crater was discovered in a scientific expedition in 1931, then Boxhole (NT) in 1937, Dalgaranga (WA) in 1938, and Wolfe Creek (WA) in 1947 (Haines, 2005). But these are small, young and simple craters which are preserved. There are some scattered meteorite fragments around the craters, and sometimes impact glasses can be found in them (Haines, 2005). In this type of crater, the obvious debris of the meteorite and the crater structure can easily prove an impact origin.

In recent years, with the continuous expansion of large-area aeronautical exploration coverage in Australia, the discovery rate at new sites has accelerated. However, potential impact structures still need further investigation. Many buried geophysical identification sites require drilling, but drilling is rarely conducted unless there is suspicion of commercial potential because of the expense. 


\subsection{The impact record from Western Australia}

Western Australian mineral resources rank first in Australia, mainly including iron, gold, nickel, diamonds, copper and oil, and have large reserves, wide distribution and high potential for development. Western Australia's mineral resources industry accounts for $86 \%$ of the Australian mineral resources industry. (Kelly and Playford, 2016). Of all mining resources in Western Australia, iron ore, petroleum and nickel ore are the three fastest growing industries, which account for about $75 \%$ of the total value of all mining resources. Almost all of Australia's nickel mineral resources come from Western Australia. In 2007, nickel production in Western Australia was 13\% of the world. (Kelly and Playford, 2016).

In Western Australia, the evolution of tectonics is not limited to geological processes of millions of years. In some special cases, the current structure is caused by the collision of meteorites or asteroids with the Earth. (Shoemaker, 1985). There are 11 impact structures in Western Australia. Most of the craters have not been drilled but most of them are exposed, the only drilled one is Woodleigh, but this one is not exposed. Most are not easily identifiable, but some form significant geological features. But there are no reported economic deposits thus far.

\section{Discussion and Conclusion}

Above all, meteor impact is an indispensable process in the geological evolution of the Earth. By analysing the above data, most scholars support the impact of impact structures on mineralization. More than 190 impact structures have been discovered in the world. New structures have been discovered and recorded each year, but there are still more to be discovered. Most impact structures have been determined to be conducive to the formation of various types of metal and non-metallic deposits. Australia, as the major mineral producing country in the world today, has many craters that are identified or need to be determined, but only three of them have been explored, including only one in Western Australia. Therefore, many potential deposits could not be explored. This has led to Australia lagging behind other countries in the exploitation of the crater deposits, and geologists are in urgent need of detailed drilling investigations in these areas. Experience has shown that the determination of many large-scale impact structures has been repeatedly explored for decades. In view of the status of Australia's meteorite impact structure. Starting from known data, researchers should strengthen comprehensive research on areas where impact structures have been found, and use methods such as petrology, tectonics, remote sensing geology and geophysics to study, and it is certain that there will be more discoveries.

\section{References}

[1] 2018. Earth Impact Database. http://www.passc.net/EarthImpactDatabase/index.html

[2] Fang, J.J., Wang, J.Q., Qiu, X. W., Gao, F.F., Gao, X.K., 2008. Geoscience Significance and Identification of Meteorite Impact Structure. Journal of Earth Sciences and Environment 30, 234-239

[3] French, B.M., Koeberl, C., 2010. The convincing identification of terrestrial meteorite impact structures: What works, what doesn't, and why. Earth-Science Reviews 98, 123-170.

[4] Haines, P.W., 2005. Impact cratering and distal ejecta: the Australian record. Australian Journal of Earth Sciences, 52:4-5, 481-507.

[5] Hamilton, C.J. Terrestrial Impact Craters .2001, http: www. solar views .com/eng/tercrate.html

[6] Grieve, R., Pilkington, M., 2002. The recognition of terrestrial impact structures. Bulletin of the Czech Geological Survey 77, 253-263.

[7] Grieve, R., 1990. Meteorite impact studies featured in Australia-Perth, Australia,17-21 September 1990.Episodes 13, 281-282.

[8] Grieve, R.A., 2005. Economic natural resource deposits at terrestrial impact structures. Geological Society, London, Special Publications 248, 1-29. 
[9] Grieve, R.A., 2013. Economic deposits at terrestrial impact structures. Impact Cratering: Processes and Products, 177-193.

[10] Grieve, R.A., Stöffler, D., 2012. Impacts and the Earth: a perspective. Elements 8, 11-12.

[11] Kelly, D. R., Playford, P. E., 2016. Geological Survey of Western Australia 2015-2016, Geology and Mineral Resources of Western Australia: Western Australia Geological Survey, Memoir 3, 827p.

[12] Kring, D.A., 2007. Guidebook to the geology of barringer meteorite crater, arizona (aka Meteor Crater). Lunar and Planetary Institute Houston.

[13] Lazorek, M., Eyles, N., Eyles, C., Doughty, M., L'Heureux, E., Milkereit, B., 2006. Late Quaternary seismostratigraphy of Lake Wanapitei, Sudbury, Ontario, Canada: Arguments for a possible meteorite impact origin. Sedimentary Geology 192, 231-242.

[14] Mashchak, M.S., Naumov, M.V., 2005. Late modification-stage tectonic deformation of the Popigai impact structure, Russia.2005 ibid, 191-210.

[15] Minz, F., 2010. Impact-related ore deposits. Department of Mineralogy, Technical University Bergakademie Freiberg.

[16] Reimold, W.U., Koeberl, C., Gibson, R.L., Dressler, B.O., 2005. Economic mineral deposits in impact structures: a review, Impact tectonics. Springer, pp. 479-552.

[17] Shoemaker, E., Shoemaker, C., 1985. Impact structures of western Australia. Meteoritics 20, 754.

[18] You, Z. D., Liu, W., 2008. Research status and prospects of impacting tectonics of meteorite. Journal of Geomechanics 14, 22-36.

[19] Zhai, G.Y., Ou, Q., Chang, X., 2001. New progress in research on impact structures at home and abroad. Geoscience Frontier 8, 0-0. 